\title{
Lithium solid electrolytes and their applications
}

\author{
D N BOSE and D MAJUMDAR \\ Materials Science Centre, Indian Institute of Technology, Kharagpur 721 302, India
}

\begin{abstract}
The preparation, characterisation and applications of two systems of lithium ion conductors, lithium zinc germanate (Lisicon) and lithium germanate vanadate are described. Ionic conductivity studies include ac conductivity, thermopower and NMR which provide complementary information. High pressure studies and fabrication of a solid-state cell are also reported.
\end{abstract}

Keywords. Lithium ion conductors; NMR; high pressure; ionic conductivity. studies; thermopower.

\section{Introduction}

Solid-state ionics is a developing field in which fundamental interest in the dynamics of ionic motion is matched by a multiplicity of possible technological applications. Among these are electrochromic displays, solid state sensors, thermoelectric devices, fuel cells and finally solid state batteries. As is well known, energy conversion and storage are vital contemperaly problems and solid state batteries have the potential of evolving into much-needed storage elements to complement silicon solar cells. However, while new concepts and materials in photovoltaic energy conversion are continuously being generated, energy storage remains in practice tradition-bound to liquid electrochemical systems.

Among solid-electrolyte systems lithium due to its low atomic weight and highly electropositive nature holds a special place. These properties lead to the possibility of high energy storage density and cell voltages up to $3 \mathrm{~V}$. Further, the metal is relatively easy to handle at room temperature and is also less expensive than noble metals such as silver. A number of cathode materials with high lithium diffusion coefficients are also available, some of which utilise the phenomenon of intercalation.

The outstanding problem with most solid electrolytes is their comparatively low conductivity near ambient temperatures. Most lithium solid electrolytes for example have appreciable conductivity only above $250-300^{\circ} \mathrm{C}$. Electrode and electrolyte stability over long periods are also remnant problems.

In this paper we review the properties of some lithium ion conducting systems investigated by us. These are lithium germanates (which includes Lisicon) and lithium germanate vanadates. The work involves the preparation of the mixed oxide systems, characterization using $\mathrm{x}$-ray diffraction, DTA and TGA studies, measurements of ionic conductivity, thermopower, NMR line narrowing and also high pressure ionic conductivity studies reported here for the first time. The fabrication of a fully solid-state battery is also described. 


\section{Structure and preparation}

The materials studied belong to two systems:

(i) $\mathrm{Li}_{16-2 x} \mathrm{D}_{x}\left(\mathrm{TO}_{4}\right)_{4}$ where $D$ is a divalent cation $\left(\mathrm{Zn}^{2+}\right.$ or $\left.\mathrm{Mg}^{2+}\right), T$ is a tetravalent cation $\left(\mathrm{Si}^{4+}\right.$ or $\left.\mathrm{Ge}^{4+}\right)$ and $0<x<4$.

(ii) $\mathrm{Li}_{3+x} \mathrm{Ge}_{x} V_{1-x} \mathrm{O}_{4}(0 \cdot 25 \leqslant x \leqslant 0 \cdot 75)$.

A representative of the first system is $\mathrm{Li}_{14} \mathrm{Zn}\left(\mathrm{GeO}_{4}\right)_{4}$ which was first studied by Hong (1978) who named it Lisicon for lithium superionic conductor. At $573 \mathrm{~K}$ its conductivity was $1.3 \times 10^{-1} \mathrm{ohm}^{-1} \mathrm{~cm}^{-1}$, the highest for any lithium ion conductor at this temperature. The crystal structure was orthorhombic and may be visualised as comprising a rigid network structure consisting of $\left[\mathrm{Li}_{11} \mathrm{Zn}\left(\mathrm{GeO}_{4}\right)_{4}\right]^{3-}$, the remaining $3 \mathrm{Li}^{+}$ions which give rise to ionic conductivity being distributed among interstitial sites.

The second system first investigated by Kuwano and West (1980) is a member of the solid solution $\mathrm{Li}_{3} \mathrm{VO}_{4}-\mathrm{Li}_{4} \mathrm{GeO}_{4}$. The compounds have tetrahedral structure with a high concentration of interstitial $\mathrm{Li}^{+}$ions. Bruce and West (1980) studied the phase diagram of Lisicon and reported that this particular composition was unstable with respect to annealing at high temperatures resulting in precipitation of $\mathrm{Li}_{4} \mathrm{GeO}_{4}$. The compound was also very susceptible to atmospheric attack. It was suggested that the composition $\mathrm{Li}_{12} \mathrm{Zn}_{2}\left(\mathrm{GeO}_{4}\right)_{4}$ would be more stable as regards both these factors. Thus the present investigations examine both compositions in some detail.

There has been some disagreement regarding the magnitude of the ionic conductivity of Lisicon at $300^{\circ} \mathrm{C}$ since later workers (e.g. von Alpen et al 1978) obtained values near $1.25 \times 10^{-2} \mathrm{ohm}^{-1} \mathrm{~cm}^{-1}$ using complex plane impedance techniques. The activation energies were also much higher, $0.42-0.56 \mathrm{eV}$ as compared to $0.24 \mathrm{eV}$ found by Hong (1978).

Thus there is considerable interest in examining the ionic conductivity and atmospheric stability of these compounds. The moisture sensitivity has been clearly delineated in the present studies by studying the effects of aging on ionic conductivity as well as on NMR, the detection of proton resonance signals giving a direct indication of the presence of water.

For preparation of Lisicon, mixtures of $\mathrm{Li}_{2} \mathrm{CO}_{3}, \mathrm{ZnO}$ and $\mathrm{GeO}_{2}$ were taken in stoichiometric proportions and then fired first in the temperature range $700-750^{\circ} \mathrm{C}$ for $5-6 \mathrm{hr}$ in order to drive off $\mathrm{CO}_{2}$. The temperature was then slowly increased in the range $900-950^{\circ} \mathrm{C}$ and maintained for $2-3 \mathrm{hr}$ cold-pressed specimens being sintered thereafter in air for $2 \mathrm{hr}$ at $1000^{\circ} \mathrm{C}$. The densities of the polycrystalline samples thus obtained were between $85-90 \%$ of the theoretical value.

For the vanadates with the generic formula $\mathrm{Li}_{3+x} \mathrm{Ge}_{x} \mathrm{~V}_{1-x} \mathrm{O}_{4}, x$ was varied from 0.25 to 0.75 . Samples were prepared by solid state reaction between appropriate proportions of $\mathrm{Li}_{4} \mathrm{GeO}_{4}$ and $\mathrm{Li}_{3} \mathrm{VO}_{4}$ and fired at temperatures between $800-1000^{\circ} \mathrm{C}$.

\section{Characterization}

Samples prepared were characterized using $x$-ray powder diffraction, the results obtained being in agreement with those of other workers. Results of DTA and TGA studies at heating rates of $10^{\circ} \mathrm{C} / \mathrm{min}$ were carried out on aged samples of compound $A$ $\mathrm{Li}_{14} \mathrm{Zn}\left(\mathrm{GeO}_{4}\right)_{4}$ as well as compound $\mathrm{B} \mathrm{Li}_{12} \mathrm{Zn}_{2}\left(\mathrm{GeO}_{4}\right)_{4}$. One endothermic peak associated with weight loss was observed for both compounds at $373 \mathrm{~K}$ while the 
second peaks were observed at $943 \mathrm{~K}$ and $913 \mathrm{~K}$ respectively. These may be associated with loss of water molecules from the intergrain region at lower temperature and from within the grains at higher temperature. The results are discussed in greater detail in conjunction with NMR experiments. For vanadates DTA and TGA results were similar to those obtained with Lisicon indicating three peaks one at $\sim 353 \mathrm{~K}$ and the other two between 900 and $1023 \mathrm{~K}$. The effect of moisture absorption was more prominent for samples with lower lithium content.

\section{Ionic conductivity and NMR studies}

\subsection{Lisicon}

Ionic conductivity measurements were carried out using ac impedance technique at frequencies between $20 \mathrm{~Hz}-100 \mathrm{kHz}$. Details of measurement techniques and interpretation of the complex plane plots have been reported elsewhere (Majumdar et al 1983). From plots shown in figure 1, the intergrain and intragrain resistances associated with the low and high frequency semi-circles respectively have been obtained at temperatures between 306 and $578 \mathrm{~K}$. The activation energies for compounds A and B thus determined are given in table 1 . The intragrain activation energies $(0.60$ and $0.47 \mathrm{eV}$ respectively) were much larger than the intergrain energies $(0.38$ and $0.35 \mathrm{eV})$.

The thermoelectric powers of the compounds determined were found to be negative for both compounds. The activation energies were 0.59 and $0.50 \mathrm{eV}$ respectively for the two compounds, in close agreement with the intragrain activation energies.

NMR line narrowing was observed for both compounds, the onset being at $230 \mathrm{~K}$ for $\mathrm{A}$ and at $240 \mathrm{~K}$ for $\mathrm{B}$. A plot of $1 / \tau$ vs $1 / T$, where $\tau$ is the ionic hopping time, is shown in figure 2 from which activation energies for ionic motion were 0.19 and $0.17 \mathrm{eV}$

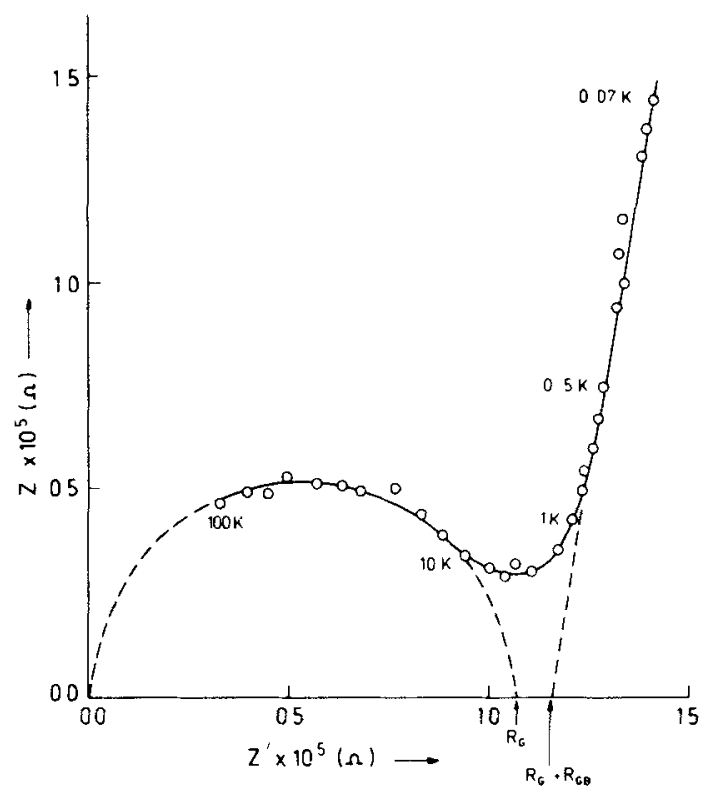

Figure 1. Complex plane impedance plot for compound A. $R_{\mathrm{G}}$ and $R_{\mathrm{GB}}$ are grain and grain boundary resistances respectively. 


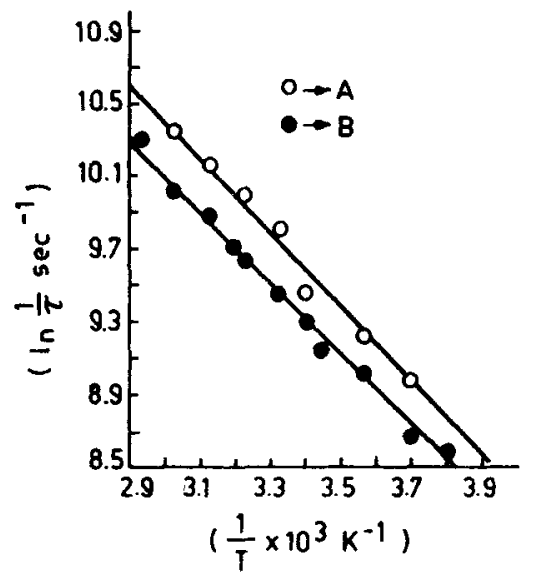

Figure 2. Ln $1 / \tau$ vs $10^{3} / T$ for compounds $A$ and $B$.

Table 1. Intragrain conductivity $\left(\sigma_{G}\right)$, intragrain and intergrain activation energy in Lisicon compounds.

\begin{tabular}{|c|c|c|c|c|}
\hline \multirow[t]{2}{*}{ Compounds } & \multicolumn{2}{|c|}{$\sigma_{G}\left(\mathrm{ohm}^{-1} \mathrm{~cm}^{-1}\right)$ at } & \multicolumn{2}{|c|}{ Activation energy $(\mathrm{eV})$} \\
\hline & $306 \mathrm{~K}$ & $578 \mathrm{~K}$ & $\begin{array}{c}\text { Int ragrain } \\
\left(E_{G}\right)\end{array}$ & $\begin{array}{c}\text { Intergrain } \\
E_{G B}\end{array}$ \\
\hline $\mathrm{Li}_{14} \mathrm{Zn}\left(\mathrm{GeO}_{4}\right)_{4}$ & $1.3 \times 10^{-6}$ & $2.47 \times 10^{-2}$ & 0.60 & $0 \cdot 38$ \\
\hline $\mathrm{Li}_{12} \mathrm{Zn}_{2}\left(\mathrm{GeO}_{4}\right)_{4}$ & $3.82 \times 10^{-6}$ & $9.47 \times 10^{-3}$ & $0 \cdot 47$ & $0 \cdot 35$ \\
\hline
\end{tabular}

Table 2. Conductivity and activation energy (deduced from conductivity and NMR) in $\mathrm{Li}_{3+x} \mathrm{Ge}_{x} \mathrm{~V}_{1-x} \mathrm{O}_{4}(0.25 \leqslant x \leqslant 0.75)$.

\begin{tabular}{lcccc}
\hline Compound & \multicolumn{2}{c}{$\sigma\left(\mathrm{ohm}^{-1} \mathrm{~cm}^{-1}\right)$ at } & & \\
\cline { 2 - 5 } & $306 \mathrm{~K}$ & $473 \mathrm{~K}$ & $\begin{array}{c}E_{\sigma} \\
(\mathrm{eV})\end{array}$ & $\begin{array}{c}E_{\mathrm{NMR}} \\
(\mathrm{eV})\end{array}$ \\
\hline $\mathrm{Li}_{3.25} \mathrm{Ge}_{0.25} \mathrm{~V}_{0.75} \mathrm{O}_{4}$ & $2.26 \times 10^{-6}$ & - & & 0.41 \\
$\mathrm{Li}_{3.6} \mathrm{Ge}_{0.6} \mathrm{~V}_{0.4} \mathrm{O}_{4}$ & $5.14 \times 10^{-6}$ & $2.11 \times 10^{-3}$ & 0.48 & 0.44 \\
$\mathrm{Li}_{3.67} \mathrm{Ge}_{0.67} \mathrm{~V}_{0.33} \mathrm{O}_{4}$ & $1.75 \times 10^{-6}$ & $7.25 \times 10^{-4}$ & 0.485 & 0.41 \\
$\mathrm{Li}_{3.72} \mathrm{Ge}_{0.72} \mathrm{~V}_{0.28} \mathrm{O}_{4}$ & $7.35 \times 10^{-7}$ & $4.27 \times 10^{-4}$ & 0.49 & 0.42 \\
$\mathrm{Li}_{3.75} \mathrm{Ge}_{0.75} \mathrm{~V}_{0.25} \mathrm{O}_{4}$ & $5 \times 10^{-7}$ & $2.03 \times 10^{-4}$ & 0.48 & 0.43 \\
\hline
\end{tabular}

respectively for compounds A and B. After storage of samples over a few weeks the narrow ${ }^{7} \mathrm{Li}$ NMR line decreased in intensity, while $a^{1} \mathrm{H}$ NMR line appeared indicating the presence of water molecules.

\subsection{Lithium germanate vanadates}

Complex impedance plots for these compounds did not yield complete semicircles due to frequency limitation but the activation energies for intragrain and intergrain conduction could nevertheless be deduced as before. The results are shown in table 2 
and indicate an intragrain activation energy of approximately $0.49 \mathrm{eV}$ for all the compositions. In this case fairly good agreement was obtained with the NMRdetermined activation energy which was $0.41-0.44 \mathrm{eV}$.

The effect of aging resulted in a reduction of conductivity by a factor of 3-4 and in an increase in the intragrain activation energy to $0.66 \mathrm{eV}$. Moisture absorption was directly indicated by the appearance of a strong ${ }^{1} \mathrm{H}$ NMR line.

\section{High pressure studies}

Ionic conductivity measurements have surprisingly remained limited to pressures below $10-15 \mathrm{~kb}$, in which range small monotonic variations have been noted for compounds such as the mixed silver iodides. Present experiments were conducted at pressures up to $80 \mathrm{~kb}$ in a tungsten carbide anvil apparatus employing four-point probes and yielded a wealth of data. At low pressures for all the compounds investigated there was a decrease in conductivity or an increase in resistivity by a factor varying from 1.13 to 1.42 . After a resistance maximum at pressures between $20-25 \mathrm{~kb}$ for compounds $\mathbf{A}$ and $\mathbf{B}$ the resistivity decreased sharply and levelled off at the highest pressures. The pressure variation of the vanadates is shown in figure 3 , the resistivity being observed to decrease by a factor of 250 at the highest pressure in fresh specimens. On aged specimens the variation of resistivity was much less while the resistivity maxima increased to higher pressures.

Examination of the pressure dependence as a function of temperature enabled the

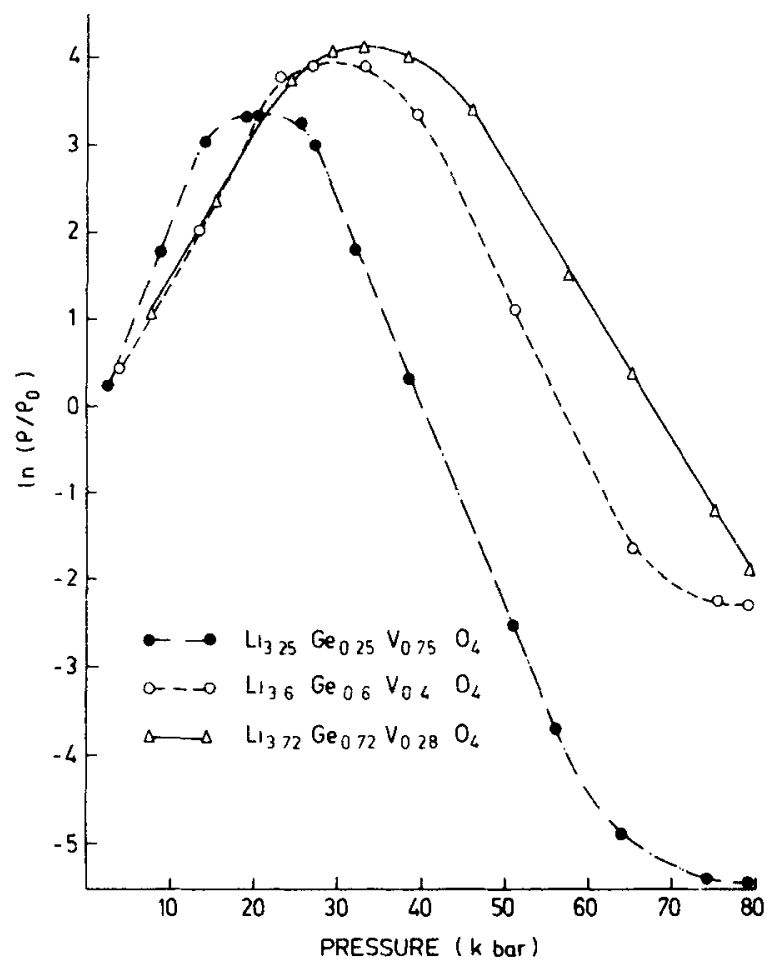

Figure 3. In $\left(\rho / \rho_{0}\right)$ vs pressure for lithium germanate vanadates. 
determination of the variation of activation energy and pre-factor $\sigma_{0}$ with pressure. It was thus found that both went through maxima at $20-25 \mathrm{~kb}$ for Lisicon.

One possible interpretation of the observed behaviour is that the bottlenecks between which the lithium ions move are reduced in size with the application of pressure thus increasing the activation energy. Thereafter a phase transition occurs as observed in many related lithium compounds (Liebertz and Rooymans 1967) resulting in a sharp decrease in activation energy. Alternative interpretations involve the initial decrease in entropy with pressure but a discontinuous change in activation volume need be invoked to explain the pronounced resistivity maxima. The aging effect due to the inhibition of lithium ion motion by adsorbed water not only reduces the variation in resistivity with pressure, but also shows that such motion of lithium ions is necessary for the observed resistivity maximum as would be the case for a displacive phase transition. This may account for the displacement of the resistivity maxima to high pressures in all cases.

\section{Solid-state cell}

A rechargeable solid-state cell was fabricated to demonstrate the potential of lithium solid electrolytes. In this case the structure was:

$$
\mathrm{Li}_{0.5} \mathrm{VO}_{2} / \mathrm{Li}_{3.6} \mathrm{Ge}_{0.6} \mathrm{~V}_{0.4} \mathrm{O}_{4} / \mathrm{TiS}_{2} \text {. }
$$

Here $\mathrm{Li}_{0.5} \mathrm{VO}_{2}$ was used as the lithium source which acted as the anode and $\mathrm{Li}_{3.6} \mathrm{Ge}_{0.6} \mathrm{~V}_{0.4} \mathrm{O}_{4}$ as the solid electrolyte since it showed the highest conductivity among the vanadate systems studied. $\mathrm{TiS}_{2}$ which is a good electronic conductor was used as the cathode which can intercalate lithium ions. The overall cell reaction is given by

$$
\mathrm{Li}_{0.5} \mathrm{VO}_{2}+\mathrm{TiS}_{2}=\mathrm{Li}_{0.5} \mathrm{TiS}_{2}+\mathrm{VO}_{2} \text {. }
$$

The cell was prepared by pressing the sandwich structure inside a steel die at a pressure of 2 tonnes/inch ${ }^{2}$. The cell characteristics were studied at $473 \mathrm{~K}$ where a maximum open-circuit voltage of $0.5 \mathrm{~V}$ and a current of $5 \times 10^{-6} \mathrm{~A} / \mathrm{cm}^{2}$ was obtained. During discharge lithium ions moved into $\mathrm{TiS}_{2}$ from the electrolyte while during the charging cycle externally applied potential drove the lithium ions back into the anode. Considering the free energy of the above reaction, the theoretical value of open-circuit voltage was calculated to be $0.52 \mathrm{eV}$ in good agreement with the experimental value. The cell could be discharged and recharged over 20 times although with somewhat diminishing performance.

\section{Discussion}

While lithium ionic conductivities up to $2.47 \times 10^{-2} \mathrm{ohm}^{-1} \mathrm{~cm}^{-1}$ at $578 \mathrm{~K}$ have been found for Lisicon and $2.11 \times 10^{-3} \mathrm{ohm}^{-1} \mathrm{~cm}^{-1}$ at $473 \mathrm{~K}$ for $\mathrm{Li}_{3.6} \mathrm{Ge}_{0.6} \mathrm{~V}_{0.4} \mathrm{O}_{4}$, high conductivity at room temperature is yet to be attained. Shahi and Wagner (1982) had reported the use of a dispersed insulating phase to enhance ionic conductivity in silver ion conductors. However, such an approach of incorporating alumina or silica when tried with the present systems did not provide encouraging results.

For high conductivity while the lithium ion concentration was important at high 
temperatures, the concentration of vacant interstitial sites as well as high lithium ion mobility were important factors specially at intermediate temperatures. This was exemplified by the occurrence of highest conductivity for $x=0.6$ in the vanadate system.

The observed conductivities were less than the highest reported in the literature. Although this may be due to differences in sintering procedure and grain size, it is more likely to be due to the high moisture sensitivity of the compounds. The NMR technique was very suitable for detecting presence of water in compounds which inhibited both inter and intragrain conduction. However, while NMR generally sensed short-range motion, ionic conductivity and thermopower were determined by long-range motion with the resultant difference in activation energies.

The high pressure studies provided first observation of pronounced resistivity maxima in solid electrolytes. Further work is obviously required to establish the occurrence of a phase transition which is considered to lead to enhanced conductivity at high pressures. Measurements on single crystals may also throw light on the high pressure behaviour. However, on polycrystalline samples it is apparent that both intergrain and intragrain motions are affected. Chemical methods of structural modification to mimic high pressure behaviour may result in the much-desired high conductivity near room temperature. Alternative approaches may involve the use of r.f. sputtered thin films as recently reported (Ohtsuka and Yamaji 1983). The realisation of high cell voltages necessitates the use of anode material such as LiSi or LiAl with high lithium activity. The study of the stability of electrode-electrolyte systems then becomes of utmost importance for the realisation of practical solid-state batteries.

\section{Conclusions}

The properties of lithium ion conducting mixed oxides have been examined using a number of techniques. It is shown that complex-plane impedance plots are essential in separating the different components that contribute to conduction and in determining their activation energies. NMR provides a valuable tool in examining microscopic motion as also the effects of moisture. High pressure studies have demonstrated for the first time pronounced conductivity minima followed by enhanced conductivity. Finally a solid state battery using lithium intercalation has been fabricated and tested.

\section{Acknowledgements}

The authors thank Prof. M Bose and Dr A Basu for fruitful collaboration in the NMR measurements and Prof. E S R Gopal and G Parthasarathy for the excellent high pressure studies. They are grateful to the Indian National Science Academy for a project which initiated the work.

\section{References}

Alpen U V, Bell M F, Wicheihaus W, Cheung K Y and Dudley G J Electrochim. Acta 1978231395 Bruce P G and West A R 1980 Mater. Res. Bull. 15379

Hong H Y P 1978 Mater. Res. Bull. 1311 ? 
Kuwano J and West A R 1980 Mater. Res. Bull. 151661

Liebertz J and Rooymans 1967 Solid State Commun. 5405

Majumdar D, Bose D N, Mukherjee M L, Basu A and Bose M 1983 Mater. Res. Bull. 1879

Ohtsuka H and Yamaji A 1983 Solid State Ionics 843

Shahi K and Wagner J B 1982 J. Solid State Chem. 42107 